\title{
The Effect of Cement Replacement with Plastic Bag Wastes (PE) and Polymer Fiber on the Concrete Performance
}

\section{Mushtaq Ahmad1, Layth Salman Khalid², Aneel Manan ${ }^{3}$, Muhammad Umar, Sharina Ibrahim ${ }^{5}$}

${ }^{1}$ Department of Engineering, Tenaga Nasional Universiti Malaysia, (Uniten) Kajang Campus.

${ }^{2}$ School of Engineering, University tun hussein onn Malaysia (UTHM).

3-4 Dept: of Civil Engineering; Swedish College of Engineering \& Technology Wah cant.

${ }^{5}$ Centre of Postgraduate Studies,UiTM Shah Alam,Malaysia.

*Corresponding Author Email: ma_5099@yahoo.com

Abstract: Plastic bag wastes (PE) are used to improve the workability of concrete and expected to reduce the plastic wastes in our environment. Polymer products such as synthetic fibers, plastics and rubbers are belonged to petrochemical compound and considered as non-biodegradable materials. One way of reducing the plastic wastes is by utilizing the plastic wastes in the production of concrete. This study investigates the dry density properties of concrete that utilize plastic wastes and polymer fiber to replace the cement, followed by finding the compressive, tensile and flexural strength of the concrete and finally, to compare the performance of concrete that utilize plastic wastes and polymer fiber vs. concrete with plastic wastes only. An extensive experimental study has been performed by utilizing the plastic wastes in concrete using a percentage of $10 \%, 20 \%$ and $30 \%$ and polymer fiber with percentage of $2 \%, 4 \%$ and $6 \%$ respectively. Results have showed the tendency of lower density in the polymer modified concrete. The utilization of waste polymer in the replacement of cement reduces compressive and flexural strength of concrete. This is probably due to bridging action provided by the fibers which absorbed more energy and prevent the sudden failure of the concrete. On the other hand, lower mechanical properties of the modified concrete that used plastic wastes and polymer fibers have been recorded in the study.

Keywords: Waste polymers, Polymer Fibers, Concrete, Cement Replacement, Compressive Strength, Flexural strength, Dry density.

\section{Introduction}

Apparently, world leaders are now taking measurements to reduce the pressure on environment created by the plastic wastes as a whole. Most recently few countries in Malaysia has banned on the use of plastic bags and added an extra charge to discourage users to reduce the use of plastic bags.

Malaysia produces 19,000 tons/day wastes and expected to reach up to 30,000 tons/day in 2020 [1]. Recycling, reusing, incineration and land fillings are the methods used to manage the wastes in general. Among these methods, land fillings are the most common method practiced in many countries for wastes disposing instead of recycle or reuse $[1,14]$.
National solid department Malaysia (2010) statistically data shows Malaysia recycle 3-5\% of the total generated wastes in the country.

The problem of increasing amount of solid wastes, which the major portion covered by the plastic products is putting pressure on the environment which also can caused skin problem and other diseases $[2,15]$.

Different approaches have been practiced to anticipate the issues related to the plastic wastes that jeopardize the environment. Amongst that is by utilizing the plastic wastes in the civil engineering practices. Researchers and engineers from the civil engineering are scavenging to fully utilize the 
plastic wastes or by partial substitution in the civil engineering practices. Shredded plastics have potential to partially replaced the aggregate and sand replacement in the concrete $[6,15]$. The addition of plastic wastes into the engineering and construction materials or by partial replacement of natural materials is capable of achieving engineeringly sound and environmentally friendly properties for strength and durability equivalent to and sometimes better than, materials formulated using the more expensive and increasingly unsustainable traditional construction materials such as Portland Cement (PC).

Plastic materials are known to be very flexible source for packaging and most commonly used by human beings around the world. In fact, natural gas and petrol are the sources of producing the plastic materials and approximately $4-6 \%$ of world's oils are being used to produce plastic materials [5]. Plastic are not just on material but it is the family of hundreds of other materials with different properties. Plastic family is categorized into two main groups; thermoplastic, which is a reversible and can be reshaped on cooling and heating repetitively. The example of thermoplastic is Poly Ethylene (PE), Poly
Propylene (PP), Poly Styrene (PS), Polyethylene Terephthalate (PET), Polyvinylchloride (PVC). Whereas, the second group of plastic is thermosets, which is not reversible on heating change, chemical composition or undergo on a chemical change on heating. The examples are Polyurethane (PUR), Epoxy resins, unsaturated polyester etc. The number of plastic wastes shares in the municipal solid have increased from less than $1 \%$ in 1960 s to more than $10 \%$ in 2005 in the middle -high income countries [5, 7].

The estimated number of plastic wastes produced between 1950 and 2015 was amounted to $2500 \mathrm{Mt}$ as shown Figure 1. The study found that approximately $800 \mathrm{Mt}(12 \%)$ of the plastic wastes have been incinerated, $600 \mathrm{Mt}(10 \%)$ have been recycled and more than $60 \%$ of the plastic wastes generated were wasted.

The concept of recycling and incineration was not being introduced before 1980s. Europe and china has the highest recycling rate of plastic wastes with $30 \%$ and $25 \%$ respectively in 2014. Additionally, incineration rate has also increased in Europe and chine $40 \%$ and $30 \%$ [5]. In some countries, plastic is recycling partially and fully replacement in construction materials substitutes [8].

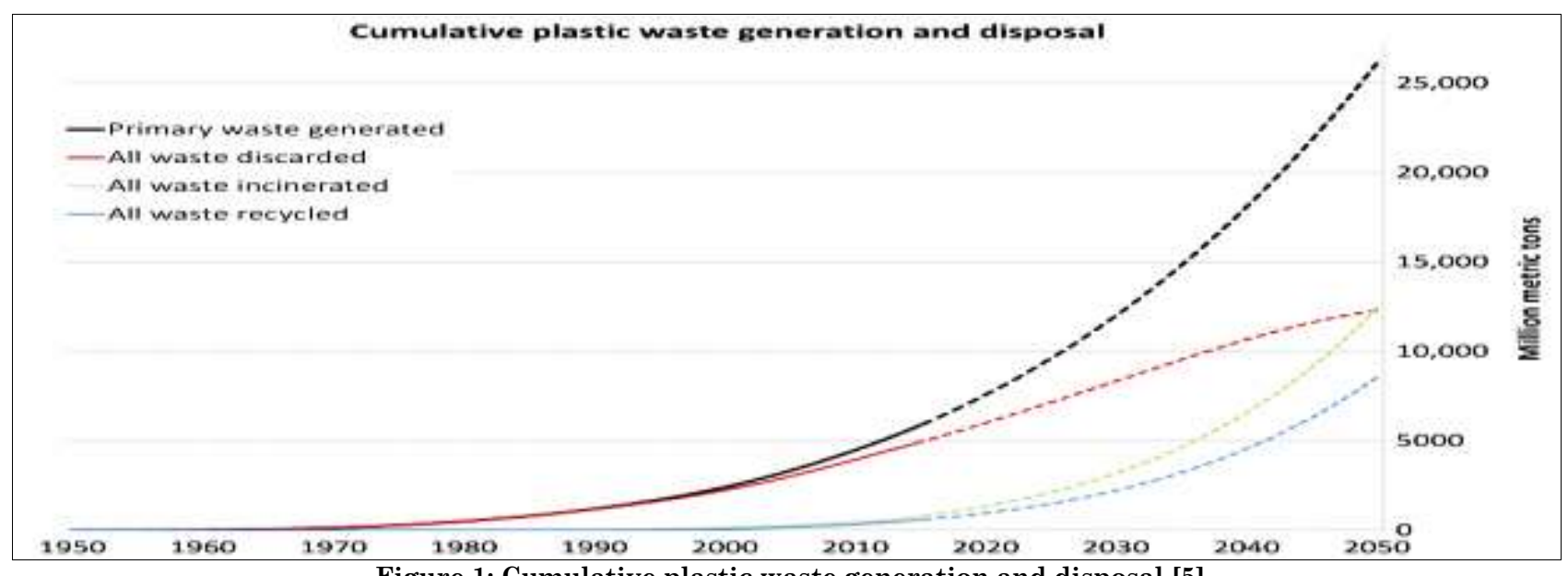

Figure 1: Cumulative plastic waste generation and disposal [5]

\section{Plastic Bag Wastes (PE) and Polymer Fibers as Construction Materials}

Disposal of plastic wastes in environment is considered as huge issue that threating the due to the fact that they are very low biodegradabile materials and presence in a very large quantity. In recent day, significant research is performed to study the possibility of utilizing the plastic wastes in mass concrete production. If plastic wastes can be mixed in the concrete mass in some form, without significant effect on its other properties or slight conciliation in strength, we can consider consuming a large quantity of plastic wastes by mixing it in the concrete mass. Plastic wastes are one component of municipal solid waste (MSW) which is becoming very relevant for the researches to 
study, due to its significant to be used in concrete, especially in self-compacting concrete and light weight concrete. Although some of the waste materials can be beneficially incorporated in concrete, both as part of the cementitious binder phase or as aggregates, it is important to realize that not all waste materials are suitable for such use.

The incorporation of plastic wastes in concrete or as a construction material is vastly studied. Saikia, [12] study the hardened properties of concrete by replacing aggregate over Polyethylene terephthalate (PET) with the ratio of 5,10 and $15 \%$. Senhadji et al [13.] Conducted study where sands and aggregates were replaced with polyvinyl chloride (PVC).

High density polyethylene (HDPE) fibers diameter $0.25 \mathrm{~mm}$ and $0.40 \mathrm{~mm}$ were studied by Pešić et al [11] and result shows 3\% improvement in tensile strength and $14 \%$ in flexural modulus. Polymer fibers majorly contribute to the serviceability properties such as plastic shrinkage cracking, drying shrinkage and reduce the water permeability [3].
There has been significant amount of research on the replacement of polymers or plastic wastes with course or fine aggregrate and few studies also has been conducted to partially replace the use of cement in concrete mass. Hence, this study is dedicated to focus on cement replacement by utilising the plastic bag wastes (PE) and polymer fibers in concrete mass.

\section{Materials and Methods}

Cement was replaced with waste polymer polyethylene (PE-10\%, 20\% and 30\%) and polymer fibers $(2 \%, 4 \%$ and $6 \%)$. The water cement ratio was kept 0.5. Extensive experimental tests such as slump test, density test, compressive and flexural strength were conducted based on the British Standard (BS) and Malaysian JKR (Public Works Department) at University Kebangsaan Malaysia (UKM).

\section{Cement}

The Ordinary Portland Cement (OPC) was being used in this study as accordance to Malaysia Standard MS 522: part 12003 and the properties of the OPC were listed in Table 1.

Table 1 : Chemical compound of cement

Table 1 : Chemical compound of cement
\begin{tabular}{|c|c|c|c|}
\hline Name of compound & Oxide Composition & Abbreviation & Percentage (\%) \\
\hline Tricalcium Silicate & $3 \mathrm{CaO} . \mathrm{SiO}_{2}$ & $\mathrm{C}_{3} \mathrm{~S}$ & 55.3 \\
\hline DicalciumSilicate & $2{\mathrm{CaO} . \mathrm{SiO}_{2}}_{2} \mathrm{~S}$ & 9.3 \\
\hline Tricalcium Aluminate & $3 \mathrm{CaO} . \mathrm{Al}_{2} \mathrm{O}_{3}$ & $\mathrm{C}_{3} \mathrm{~A}$ & 10.3 \\
\hline $\begin{array}{c}\text { Tetracalcium } \\
\text { Aliminoferrite }\end{array}$ & $4 \mathrm{CaO} \cdot \mathrm{Al}_{2} \mathrm{O}_{3} \cdot \mathrm{Fe}_{2} \mathrm{O}_{3}$ & $\mathrm{C}_{4} \mathrm{AF}$ & \\
\end{tabular}

\section{Course Aggregate}

Crushed granite stone was being used as a course aggregate and course aggregate grading was shown as in Table 2 below:

Table 2 : Course aggregate grading

\begin{tabular}{|c|c|c|}
\hline Sieve Size & Weight Retained (g) & \% Passing \\
\hline $20 \mathrm{~mm}$ & 0.84 & 90 \\
\hline $14 \mathrm{~mm}$ & 4.40 & 37 \\
\hline $10 \mathrm{~mm}$ & 0.76 & 28 \\
\hline $5 \mathrm{~mm}$ & 1.42 & 11 \\
\hline
\end{tabular}

Mix Design Composition
Mix design composition employed throughout the study was based on the recommendations by previous studies. The mix proportions were shown in Table 3.

Table 3 : Material mix design composition

\begin{tabular}{|c|c|c|c|c|c|}
\hline $\begin{array}{c}\text { Specimen } \\
\text { type }\end{array}$ & $\begin{array}{c}\text { Cement } \\
\text { content (\%) }\end{array}$ & Sand (\%) & Gravel (\%) & $\begin{array}{c}\text { Plastic Waste } \\
\text { (\%) }\end{array}$ & $\begin{array}{c}\text { Polymer Fiber } \\
\text { (\%) }\end{array}$ \\
\hline RC & 100 & 29 & 50 & 0 & 0 \\
\hline PW1 & 88 & 29 & 50 & 10 & 2 \\
\hline PW2 & 76 & 29 & 50 & 20 & 4 \\
\hline PW3 & 64 & 29 & 50 & 30 & 6 \\
\hline
\end{tabular}

Note: Weight of the material $=$ Volume of material $\left(\mathrm{m}^{3}\right) \times$ Density $\left(\mathrm{kg} / \mathrm{m}^{3}\right)$ 


\section{Results and Discussion}

\section{Slump Test}

The slump test practiced in this study for testing the workability of the fresh plastic modified concrete was as accordance to ASTM-C-143-90a and BS-1881: Part 102:
1983. Concrete was tested during its fresh and hardened state mainly to ensure that concrete mix satisfied the specification of works. The results of the slump test conducted are shown in Table 5.

Table 4: The slump test value for the modified concrete

\begin{tabular}{|c|c|}
\hline Specimen type & Slump (cm) \\
\hline RC & 4.9 \\
\hline PW1 & 5.5 \\
\hline PW2 & 5.7 \\
\hline PW3 & 6.2 \\
\hline
\end{tabular}

From the testing, it can be observed that higher slump value was achieved from the addition of plastic wastes and plastic fibers in the concrete. As shown in Table 4, the slump value for unmodified/plain concrete (RC) was recorded at $4.9 \mathrm{~cm}$. The highest slump value recorded was $6.2 \mathrm{~cm}$ when the modified concrete used plastic waste blended with polymer fiber with the content ratio of $30 \%$ and $6 \%$, respectively.

The results indicate that by utilizing higher polymer contents in the concrete mix will increase the slump value and workability of the concrete, which apparently will improve the performance of the concrete. The higher slump value also indicates the adhesiveness of the materials. The higher the slump value is, the higher adhesion will it be between cement with plastic compare to sand and aggregates.

\section{Dry Density}

The results of dry density for the modified concrete were shown in Table 5 . As can be seen in the table, the dry densities recorded for polymer modified concrete were lower as compared to the control mix concrete (RC).

Table 5 : Dry density for the modified concrete

\begin{tabular}{|c|c|}
\hline Specimen type & Bulk Density $\left(\mathrm{Kg} / \mathrm{m}^{3}\right)$ \\
\hline $\mathrm{RC}$ & 2420 \\
\hline PW1 & 2390 \\
\hline PW2 & 2310 \\
\hline PW3 & 2240 \\
\hline
\end{tabular}

In general, the water cement ratio will affect the density of the concrete. However, from the results achieved in this study, lower density of plastic possibly reduces the density of the concrete. The replacement of plastic wastes with the aggregate resulted in lower density of concrete. But, in case of light weight concrete, the result considered as more workable and reliable.

As the content of polymer increased in the concrete, the result for bulk density will be lowered. The highest reading for bulk density was recorded at $2420 \mathrm{Kg} / \mathrm{m}^{3}$ for unmodified concrete/plain concrete (RC).

Whereas, the lowest reading was recorded at $2240 \mathrm{Kg} / \mathrm{m}^{3}$ for polymer modified concrete using $30 \%$ of polymer content. Theoretically, the lower density of the polymer modified concrete might be due to the lower specific gravity of plastic materials.

\section{Compressive Strength Test}

Table 6 showed the results of compressive strength test (CS) for the modified concrete. Overall, the results for compressive strength recorded for polymer modified concrete were lower as compared to the unmodified concrete/plain concrete (RC). The highest value for compressive strength result was achieved at $29.7 \mathrm{MPa}$ for the control mix concrete/plain concrete (RC).

Whereas, the lowest compressive strength was achieved using polymer modified concrete with $30 \%$ of polymer contents at $27.66 \mathrm{MPa}$. Some of the previous studies that used polymer as cement replacement in concrete had similar results as achieved in the current study. From the results, by increasing the polymer contents in concrete will reduce the compressive strength. 
The higher concentration of waste polymers contents in concrete clearly indicates that lower compressive strength achieved for the modified concrete. This is in line with the most recent study conducted by Antil \&
Mohali [4], which concluded that lower compressive strength gained for modified concrete that utilized polymer to replace the use of cement.

Table 6 : Compressive strength for the modified concrete

\begin{tabular}{|c|c|}
\hline Specimen type & Compressive Strength (MPa) \\
\hline RC & 30.23 \\
\hline PW1 & 29.70 \\
\hline PW2 & 29.21 \\
\hline PW3 & 27.66 \\
\hline
\end{tabular}

\section{Tensile Splitting Strength}

Another important parameter to be considered in the design of any civil engineering structures is the tensile strength. As described in Table 7, the lowest tensile strength gained was $2.8 \mathrm{MPa}$ for the unmodified concrete/plain concrete (RC). When the plastic wastes and polymer fibers were added into the modified concrete using $10 \%$ and $2 \%$ contents respectively, it can be noted that the tensile strength was increased to $3.5 \mathrm{Mpa}$, approximately $25 \%$ increment as compared to unmodified concrete/plain concrete. However, it was also noted that with the percentage increase of plastic wastes and polymer fibers content in the concrete mixtures, the results for tensile strength were declined, from $3.5 \mathrm{MPa}$ to $3.1 \mathrm{MPa}$ for $10 \%$ to $30 \%$ plastic wastes contents correspondingly. There are no cementitious reactions between cement and plastic that can caused increment in tensile splitting strength.

Table 7: Tensile splitting strength for modified concrete

\begin{tabular}{|c|c|}
\hline Specimen type & Tensile Strength (MPa) \\
\hline RC & 2.8 \\
\hline PW1 & 3.5 \\
\hline PW2 & 3.3 \\
\hline PW3 & 3.1 \\
\hline
\end{tabular}

\section{Flexural Test}

Flexural strength test was conducted to evaluate the concrete's ability to withstand flexure or bending forces. As for this study, as shown in Table 8 , the modified concrete has shown lower flexural strength results as compared to the unmodified concrete/plain concrete (RC). The unmodified concrete/plain concrete has recorded the highest result of $4.7 \mathrm{Mpa}$ for flexural strength test.

However, with the addition of plastic wastes and polymer fibers into the concrete has reduced the flexural strength of the modified concrete to $4.6 \mathrm{MPa}$. Based on the results in Table 8, with increasing plastic wastes and polymer fibers utilized in the modified concrete, the flexural strengths will be decreasing. The lowest flexural strength attained in this study was $4.3 \mathrm{MPa}$ for modified concrete with $30 \%$ and $6 \%$ contents of plastic wastes and polymer fibers respectively. This is also as accordance to the study conducted by Meraj et al., [9], which also recorded lower flexural strength results for polymer concrete and stated that with the use of polymer will reduce the flexural strength of the concrete.

This is to be expected, due to bridging action provided by fibers which absorbed more energy and prevent the sudden failure of the specimen.

Table 8 : Flexural strength for modified concrete

\begin{tabular}{|c|c|}
\hline Table 8: Flexural strength for modified concrete & Flexural Strength (MPa) \\
\hline Specimen type & 4.7 \\
\hline RC & 4.6 \\
\hline PW1 & 4.5 \\
\hline PW2 & 4.3 \\
\hline PW3 & The \\
\hline
\end{tabular}

The current study utilized plastic bag wastes (PE) and polymer fiber as a cement replacement in the modified concrete. Based 
on the current findings, it can be concluded that by increasing the contents ratio of polymer fiber and plastic bag wastes (PE) will reduce the dry density of the modified concrete.

The other mechanical properties such compressive strength, tensile splitting strength and flexural strength recorded lower results for modified concrete utilizing the plastic waste and polymer fibers as compared to the unmodified concrete/plain concrete. Increasing the content of plastic wastes and polymer fibers in the modified concrete showed no significant improvement for the mechanical properties mentioned earlier. The utilization of plastic wastes as cement replacement in concrete is considered as very new development in civil engineering and construction fields. Based on this study,

\section{References}

1.Ahmad M, Ayob MB (2015) Improvement of Road Pavement Infrastructure by Using Polyethylen Terephthalate \& Polypropylene. International Journal of Advances in Mechanical and Civil Engineering, 2(3):126-134.

2.Ahmad M, Ayob MB (2016) Improvement of Asphaltic Concrete by Using Waste Polyethylen Terephthalate (PET). International Journal of Innovative Research in Science, Engineering and Technology (IJIRSET), 4(8).

3. Albano C, Camacho N, Hernandez M, Matheus A, Gutierrez A (2009) Influence of content and particle size of waste pet bottles on concrete behavior at different w/c ratios. Waste Management, 29(10):2707-2716.

4. Antil EY (2014) an experimental study on rubberized concrete. International Journal of Emerging Technology and Advanced Engineering, 4(2):309-316.

5. Geyer R, Jambeck JR, Law KL (2017) Production, use, and fate of all plastics ever made. Science advances, 3(7): e1700782.

6.Jaivignesh B, Sofi A (2017) Study on Mechanical Properties of Concrete Using Plastic Waste as an Aggregate. Paper presented at the IOP Conference Series: Earth and Environmental Science.

7.Jambeck JR, Geyer R, Wilcox C, Siegler TR, Perryman M, Andrady A, . . Law KL (2015) Plastic waste inputs from land into the ocean. Science, 347(6223):768-771.

8. Kamaruddin M, Abdullah M, Zawawi M, Zainol M(2017) Potential use of Plastic Waste as Construction Materials: Recent Progress and Future Prospect. Paper presented at the IOP Conference Series: Materials Science and Engineering. it can be concluded that, the utilization of plastic wastes and polymer fiber can be very significant and reliable for the lightweight concrete application only. However, for further improvement, it is recommended for the future study to use the plastic wastes and polymer fibers as aggregates replacement instead of cement replacement or partially being used as cement replacement in the modified concrete.

This is due to the fact that there is no cementitious reaction between plastic wastes and polymer fibers with the aggregates in the modified concrete without cement. The use of cement in the modified concrete is still to be considered for the cementations' reaction to occur.

9. Meraj T, Pandey A, Rao B (2014) Flexural behaviour of latex modified steel fiber reinforced concrete.

10. Osei DY (2014) Experimental Investigation on Recycled Plastics as Aggregate in Concrete. Int. J. Struct. Civ. Eng. Res, 3(2):168-174.

11. Pešić N, Živanović $\mathrm{S}$, Garcia R, Papastergiou $\mathrm{P}$ (2016) Mechanical properties of concrete reinforced with recycled HDPE plastic fibres. Construction and building materials, 115:362-370.

12. Saikia N, DE Brito J (2014) Mechanical properties and abrasion behaviour of concrete containing shredded PET bottle waste as a partial substitution of natural aggregate. Construction and building materials, 52:236-244.

13. Senhadji Y, Escadeillas G, Benosman A, Mouli M, Khelafi H, Ould Kaci S (2015) Effect of incorporating PVC waste as aggregate on the physical, mechanical, and chloride ion penetration behavior of concrete. Journal of Adhesion Science and Technology, 29(7):625-640.

14. Thomas R, Vijayan P, Thomas S (2011) Recycling of thermosetting polymers: their blends and composites. Recent Developments in Polymer Recycling, 121-153.

15. Tonet KG, Gorninski JP (2013) Polymer concrete with recycled PET: The influence of the addition of industrial waste on flammability. Construction and building materials, 40 . 
